\title{
Construction and analysis of a high-density genetic linkage map in cabbage (Brassica oleracea L. var. capitata)
}

Wanxing Wang ${ }^{1+}$, Shunmou Huang ${ }^{2+}$, Yumei Liu ${ }^{1 *}$, Zhiyuan Fang ${ }^{1}$, Limei Yang ${ }^{1}$, Wei Hua ${ }^{2}$, Suxia Yuan ${ }^{1}$, Shengyi Liu', Jifeng Sun', Mu Zhuang ${ }^{1}$, Yangyong Zhang ${ }^{1}$ and Aisong Zeng ${ }^{1}$

\begin{abstract}
Background: Brassica oleracea encompass a family of vegetables and cabbage that are among the most widely cultivated crops. In 2009, the B. oleracea Genome Sequencing Project was launched using next generation sequencing technology. None of the available maps were detailed enough to anchor the sequence scaffolds for the Genome Sequencing Project. This report describes the development of a large number of SSR and SNP markers from the whole genome shotgun sequence data of B. oleracea, and the construction of a high-density genetic linkage map using a double haploid mapping population.

Results: The B. oleracea high-density genetic linkage map that was constructed includes 1,227 markers in nine linkage groups spanning a total of $1197.9 \mathrm{cM}$ with an average of $0.98 \mathrm{cM}$ between adjacent loci. There were 602 SSR markers and 625 SNP markers on the map. The chromosome with the highest number of markers (186) was C03, and the chromosome with smallest number of markers (99) was C09.

Conclusions: This first high-density map allowed the assembled scaffolds to be anchored to pseudochromosomes. The map also provides useful information for positional cloning, molecular breeding, and integration of information of genes and traits in B. oleracea. All the markers on the map will be transferable and could be used for the construction of other genetic maps.
\end{abstract}

Keywords: Cabbage, Brassica, Genetic linkage map, SSR, SNP, Genome

\section{Background}

Brassicaceae is a large family, consisting of approximately 340 genera and more than 3,350 species [1]. In addition to providing vegetable oil, vegetables, fodder and condiment, Brassicas are important sources for dietary fiber, vitamin $\mathrm{C}$ and other nutritionally beneficial factors such as anticancer compounds [2]. Cytogenetic research of the six cultivated species has shown that the group includes three diploid species, $[B$. rapa (AA, $2 \mathrm{n}=20), B$. nigra $(\mathrm{BB}, 2 \mathrm{n}=16), B$. oleracea $(\mathrm{CC}$, $2 \mathrm{n}=18)]$, and three amphiploid species, $[B$. juncea (AABB, 2n=36), B. napus (AACC, $2 \mathrm{n}=38$ ) and $B$.

\footnotetext{
* Correspondence: liuym@mail.caas.net.cn

${ }^{+}$Equal contributors

'Institute of Vegetables and Flowers, Chinese Academy of Agricultural Sciences, Key Laboratory of Biology and Genetic Improvement of Horticultural Crops, Ministry of Agriculture, P.R.China. Beijing 100081, China Full list of author information is available at the end of the article
}

carinata $(\mathrm{BBCC}, 2 \mathrm{n}=34)$ ]. In addition, interspecific hybridization studies demonstrated that three diploid species contain the basic chromosome sets, while the amphiploid species contain hybridized and naturally doubled combinations of the three diploid species in a relationship that is referred to as U's triangle [3]. The genome sizes of the diploid Brassicas and the allopolyploids are 529-696 Mb and 1068-1284 Mb respectively [4].

Long-term cultivation and artificial selection of Brassica crops have resulted in rich intraspecific morphological variations all of which are adapted for various cultivation conditions [5]. For instance, well-established vegetables of the $B$. oleracea species comprise a number of morphologically diverse crops, including cabbage $(B$. oleracea var. capitata), Brussels sprouts (B. oleracea var. gemmifera), kale (B. oleracea var. acephala), kohlrabi $(B$.

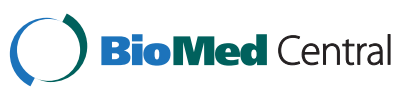


oleracea var. gongylode), Chinese kale (B. oleracea var. alboglabra), broccoli (B. oleracea var. italica) and cauliflower (B. oleracea var. botrytis).

Cabbage (B. oleracea var. capitata) is considered to be a typical representative of the $C$ genome of Brassica and the $B$. oleracea Genome Sequencing Project (BrGSP) was launched in 2009. The B. oleracea material that was used for the de novo sequencing was an advanced homozygous inbred line $02-12$. The primary sequencing project has been completed and the findings will be published shortly. To anchor the assembled scaffolds to pseudochromosomes, a high-density genetic map based on sequence-tagged PCR-markers is required.

A high-density genetic map can also form the basis for quantitative trait loci mapping (QTL mapping), marker assistant selection (MAS), and functional gene positional cloning, and will be useful for functional genomics and genetic breeding studies. A comparison of the genetic maps of closely related species will contribute to an understanding of the origin of relationships among the Brassicas, and genetic maps can provide insights into genome organization and evolution through comparative mapping.

More than ten genetic linkage maps of $B$. oleracea have been constructed [6]. The early genetic maps used restriction fragment length polymorphism (RFLP) markers [7-9]. However, RFLPs requires a large amount of DNA and the procedure is inefficient and difficult to apply in breeding. With the invention of the polymerase chain reaction (PCR), a variety of PCR-based markers, such as simple sequence repeats (SSRs) were successively developed and became the preferred markers. SSRs require only small amounts of DNA, are easily generated by PCR, are amenable to high-throughput analysis, codominantly inherited, multi-allelic, highly polymorphic, abundant, and are evenly distributed in genomes [10]. SSRs have been extensively used in tagging qualitative genes and in dissecting the genetic bases of complex traits [11-13]. Recent developments in sequencing technology have simplified and accelerated the discovery of sequence variants, enabling the development of sequence-based markers including single nucleotide polymorphisms (SNPs) and insertion/deletion polymorphism (InDel) markers [14]. SNPs are the markers of choice for high-resolution genetic mapping and association studies because of their abundance and widespread distribution throughout the genome [15]. These third generation markers, however, have rarely been used for genetic linkage mapping in B. oleracea.

$B$. oleracea genetic maps are most often constructed using populations obtained from crosses between subspecies and varieties, and $\mathrm{F}_{2}$ populations that are not immortal $[8,9] . \mathrm{F}_{2}$ mapping populations are temporary and difficult to maintain for long term and comparative studies. To produce high-resolution genetic maps for future research, double haploid (DH) and recombinant inbred line (RIL) populations are more often used for mapping. However, to date, no studies have reported the use of a $\mathrm{DH}$ population for mapping between cabbage varieties.

We generated a double haploid (DH) population derived from an $\mathrm{F}_{1}$ cross between two advanced homozygous inbred lines, $01-88$ and $02-12$, by microspore culture. A number of SSR and SNP markers were developed using the whole genome shotgun sequence data from the BrGSP. These markers were then used to construct a saturated genetic map of the B. oleracea genome that could be used to anchor and orientate sequence scaffolds from the B. oleracea genome assembly.

\section{Methods}

Development of a mapping population and DNA isolation Two diverse advanced homozygous inbred lines of cabbage, 01-88 and 02-12, were used as the parents to develop a doubled haploid (DH) mapping population containing 165 lines. The DH population was derived from the $F_{1}$ by microspore culture[16] and contained lines with a wide variety of morphological traits.

Total DNA was isolated from the expanding leaves of three-week old plants using the modified cetyltrimethylammonium bromide (CTAB) method [17]. The genomic DNA samples were adjusted to $50 \mathrm{ng} \mathrm{DNA} / \mu \mathrm{l}$ and preserved at $-20^{\circ} \mathrm{C}$ until used as the templates for PCR amplification. Additional, leaf tissue was lyophilized for use in future experiments.

\section{Marker sources}

The two marker types (SSRs and SNPs) were obtained from seven sources including genomic DNA sequence data and gene or EST databases (Table 1). A total of 3,378 SSR markers were developed from the cabbage

Table 1 Source of the sequences and primers that were used in this study

\begin{tabular}{|c|c|c|}
\hline Code of primers & $\begin{array}{l}\text { Number of } \\
\text { primers }\end{array}$ & Source of primers \\
\hline $\mathrm{Cl}, \mathrm{sC}$ & 3378 & Sequencing of $B$. oleracea \\
\hline snap & 2200 & Resequencing of $B$. oleracea \\
\hline $\mathrm{Ra}, \mathrm{ol}, \mathrm{Na}, \mathrm{FITO}$ & 551 & Public B. oleracea markers [18-22] \\
\hline BoE & 1080 & $\begin{array}{c}\text { Associate researcher Zhuang in } \\
\text { IVF CAAS [23] }\end{array}$ \\
\hline BnGMS & 268 & $\begin{array}{c}\text { Professor Liu in Huazhong Agricultural } \\
\text { University }[6,24]\end{array}$ \\
\hline brbac & 292 & BAC database of $B$.rapa \\
\hline brsf & 728 & Sequencing of $B$. rapa \\
\hline Total & 8497 & \\
\hline
\end{tabular}


sequence scaffolds and 2,200 SNP markers were developed by resequencing the other parent (line 01-88) of the $B$. oleracea mapping population. The 551 published SSR primer pairs derived from the genomic sequences of $B$. rapa (prefixed by $\mathrm{Ra}), B$. oleracea $(\mathrm{ol}), B$. napus $(\mathrm{Na})$ and $B$. nigra $(\mathrm{Ni})$, were obtained from the BrassicaDB database [18-21]. The FITO markers were designed by Iniguez-Luy [22]. A total of 62,567 ESTs in B. oleracea were downloaded from the National Center for Biotechnology Information (NCBI) for the identification and development of 1,080 EST-SSR markers [23]. Professor Liu Kede from Huazhong Agricultural University developed 268 markers with the data from the brassica.info database $[6,24]$. The data for the BAC end sequencing generated 292 SSR markers. The remaining 728 SSRs were derived from the B. rapa genome. A total of 8,497 primer sets were developed for the 6,297 SSR and 2,200 SNP markers and used to scan for polymorphisms between two parents.

\section{Analysis of molecular markers SSR detection}

The process used for SSR markers development is presented in Figure 1. First, All SSRs were identified and selected using MISA [25] in the assembled sequences and expressed sequence tags. The minimum repeat units for MNRs (mononucleotides repeats), DNRs (dinucleotide repeats), TNRs (trinucleotide repeats), TTRs (tetranucleotide repeats), PNRs (pentanucleotide repeats), and HNRs (hexanucleotide repeats) were chosen to be 10, 6, $5,5,5$, and 5, respectively. The maximum difference was 100 base pairs between two SSRs.

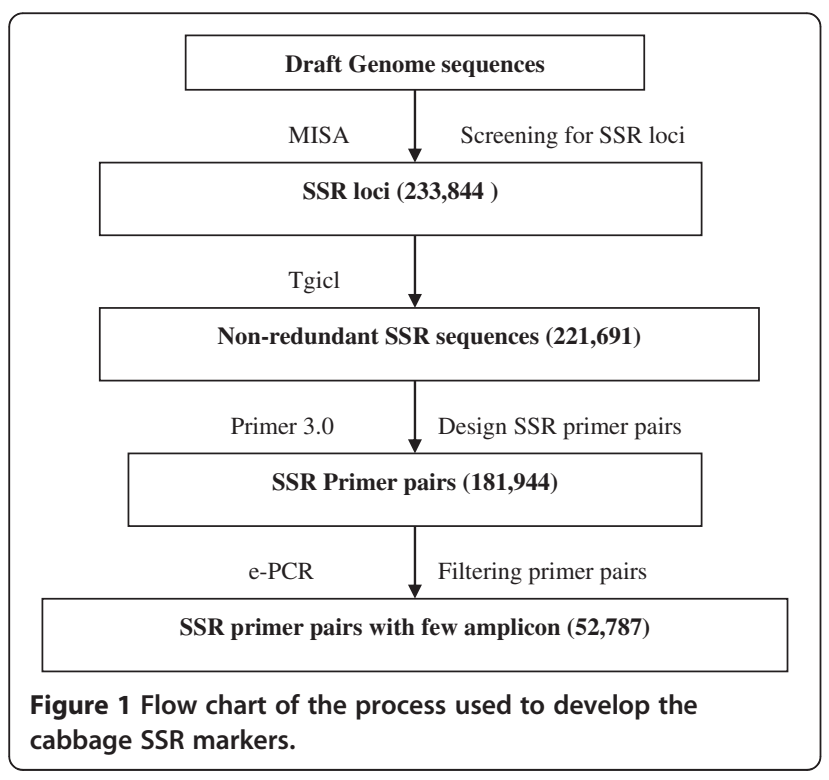

\section{SSR markers}

First, the redundant SSR-containing sequences were identified by tgicl software (http://compbio.dfci.harvard. edu/tgi/software/). Second, SSR primer pairs were designed using the Primer 3.0 program [26]. The primer lengths ranged from 18 to 23 nucleotides, with an optimum size of 20 nucleotides. The melting temperatures ranged from 50 to $65^{\circ} \mathrm{C}$, with an optimum temperature of $55^{\circ} \mathrm{C}$. The optimum GC content was set to $50 \%$, with a minimum of $40 \%$ and a maximum of $60 \%$. The predicted PCR products ranged from 200 to $300 \mathrm{bp}$. Third, the primer pairs were then filtered by ePCR with default parameters [27]. All primers were synthesized by the Engineering Company, Shanghai, China.

DNA amplification of the SSR markers was carried out in volumes of $20 \mu \mathrm{l}$, containing 1 unit of Taq polymerase, $0.1 \mu \mathrm{M}$ of each of the primers, $200 \mu \mathrm{M}$ dNTPs, $2 \mu \mathrm{l}$ $10 \times$ buffer $\left(\mathrm{Mg}^{2+} 25 \mathrm{mM}\right)$ and $50 \mathrm{ng}$ of genomic DNA as templates. The PCR profile was as follows: initial $4 \mathrm{~min}$ at $94^{\circ} \mathrm{C}$, then 35 cycles, each with $30 \mathrm{~s}$ DNA denaturation at $94^{\circ} \mathrm{C}, 30 \mathrm{~s}$ annealing at $55^{\circ} \mathrm{C}$ and $60 \mathrm{~s}$ extension at $72^{\circ} \mathrm{C}$, and a final extension of $7 \mathrm{~min}$ at $72^{\circ} \mathrm{C}$. The PCR was carried out in a GeneAmp PCR system 9700 (Applied Biosystems, California, US).

\section{SNP markers}

Firstly, a lot of SNPs (unpublished data) were identified between the $01-88$ and $02-12$ by soapsnp software (http://soap.genomics.org.cn/soapsnp.html). Secondly, the SNP-contained sequences were extracted for primer design by SNAPER $[28,29]$ using the default parameters. A total of 2,200 SNPs were transferred into SNAP(Single Nucleotide Amplified Polymorphisms) makers for genotyping via PAGE (PolyAcrylamide Gel Electrophoresis). PCR amplifications were performed in a volume of $20 \mu \mathrm{l}$ containing $100 \mathrm{ng}$ genomic DNA, $1 \mu \mathrm{l} 10 \times$ Taq buffer $\left(\mathrm{Mg}^{2+} 25 \mathrm{mM}\right), 100 \mu \mathrm{M}$ dNTPs, $0.05 \mu \mathrm{M}$ each primer and 0.5 unit Taq DNA polymerase. The PCR profile was as follows: initial $4 \mathrm{~min}$ at $94^{\circ} \mathrm{C}$, then 34 cycles, each with $15 \mathrm{~s}$ DNA denaturation at $94^{\circ} \mathrm{C}, 15 \mathrm{~s}$ at the appropriate annealing temperature $\left(55-65^{\circ} \mathrm{C}\right)$ and $30 \mathrm{~s}$ extension at $72^{\circ} \mathrm{C}$, and a final extension of $7 \mathrm{~min}$ at $72^{\circ} \mathrm{C}$. The PCR was carried out in a GeneAmp PCR system 9700 (Applied Biosystems). The PCR products were separated on $8 \%$ non-denaturing polyacrylamide gels. After electrophoresis, the gels were stained as previously described [30].

\section{Linkage analysis and map construction}

For map construction, the segregation in the $\mathrm{DH}$ population was analyzed for all the SSR markers that showed polymorphisms between the parental $01-88$ and $02-12$ lines. The markers contained two types of genotypic 
data: type $\mathrm{A}$, the same as parent line $01-88$, and type $\mathrm{B}$, the same as parent line $02-12$. Data that were unclear or missing for various reasons were indicated by ' - '.

Markers which were reproducibly polymorphic between the parental lines were scored in the DH population. Linkage analysis and map construction were performed using JoinMap version 3.0 [26,31]. Linkage groups were identified in the LOD (logarithm (base 10) of odds) grouping threshold range of 5.0-10.0, and linkage groups were assigned as $\mathrm{C} 01-\mathrm{C} 09$, corresponding to the C-genome linkage groups of B. napus [32]. Maps were generated for each linkage group using a recombination frequency below 0.40 and LOD scores above 0.5 for all the markers within each linkage group. A 'ripple' procedure was performed after the addition of each marker and the 'jump' thresholds were set to 5 . Recombination frequencies were converted to centiMorgans (cM) using Kosambi's method for map-distance calculation [33].

\section{Marker distribution analysis}

To evaluate whether the mapped markers were randomly distributed on the linkage map, the linkage groups were divided into $1,2.5,5,10,20$, and $40 \mathrm{cM}$ blocks, and the number of markers per block was counted. Observed frequencies of the number of markers per block were compared with the expected ones by performing a Chi-square test, using a Poisson distribution function, $\mathrm{P}(\mathrm{x})=\mathrm{e}^{-\mu} \mu^{\mathrm{x}} / \mathrm{x}$ !, where $\mathrm{x}$ is the number of markers per block and $\mu$ is the average marker density in the consensus map. Average marker density $(\mu)$ was used to calculate the expected binomial frequencies for each marker class per block interval for all the linkage groups. The distribution of markers on the linkage groups was also evaluated separately for the SSR and SNP markers.

\section{Results}

Development of the mapping population

A total of 1,227 normal embryos were obtained from the 01-88 $\times 02-12 \mathrm{~F}_{1}$ by microspore culture. Each bud generated approximately $70-120$ embryos. After plant regeneration, 1,021 plants consisting of 170 haploids, 768 doubled diploids, 10 polyploids, and 73 chimeras were obtained. Finally, a DH population including of 165 individuals were obtained.

\section{Marker development}

A total of 233,844 putative SSR sequences were identified from the cabbage assembled scaffold sequences. The frequencies of the different types of SSRs in the genome are listed in Table 2. Six different SSR repeat types were indentified, and of these the MNRs (163,621, 69.97\%) were the most abundant and the HNRs were the least abundant $(311,0.13 \%)$. Among the DNRs, $(A T)_{n}$ was the
Table 2 Distribution of different types of SSRs in the $B$. oleracea genome

\begin{tabular}{|c|c|c|c|c|}
\hline Motifs & Number & $\begin{array}{c}\text { Percentage } \\
\text { (\%) }\end{array}$ & $\begin{array}{l}\text { Total length } \\
\text { (bp) }\end{array}$ & $\begin{array}{c}\text { Average } \\
\text { length (bp) }\end{array}$ \\
\hline Mononucletide & 163621 & 69.97 & 1952399 & 11.93 \\
\hline$A$ & 158142 & 67.63 & 1872884 & 11.84 \\
\hline C & 5479 & 2.34 & 79515 & 14.51 \\
\hline Dinucleotide & 55336 & 23.66 & 968946 & 17.51 \\
\hline AT & 33315 & 14.25 & 596070 & 17.89 \\
\hline$A G$ & 18593 & 7.95 & 322438 & 17.34 \\
\hline$A C$ & 3411 & 1.46 & 50220 & 14.72 \\
\hline CG & 17 & 0.01 & 218 & 12.82 \\
\hline Trinucleotide & 13080 & 5.59 & 254598 & 19.46 \\
\hline AAG & 4281 & 1.83 & 80493 & 18.80 \\
\hline AAT & 2535 & 1.08 & 63240 & 24.95 \\
\hline AGG & 1434 & 0.61 & 26880 & 18.74 \\
\hline AAC & 1313 & 0.56 & 22029 & 16.78 \\
\hline AGT & 1062 & 0.45 & 19302 & 18.18 \\
\hline $\mathrm{ACT}$ & 1004 & 0.43 & 18582 & 18.51 \\
\hline ACC & 795 & 0.34 & 13245 & 16.66 \\
\hline AGC & 271 & 0.12 & 4581 & 16.90 \\
\hline ACG & 225 & 0.10 & 3708 & 16.48 \\
\hline CCG & 160 & 0.07 & 2538 & 15.86 \\
\hline Tetranucleotide & 1131 & 0.48 & 26960 & 23.84 \\
\hline AAAT & 404 & 0.17 & 8916 & 22.07 \\
\hline AAAG & 152 & 0.07 & 4060 & 26.71 \\
\hline AATT & 110 & 0.05 & 2692 & 24.47 \\
\hline AAAC & 94 & 0.04 & 2108 & 22.43 \\
\hline Others & 371 & 0.16 & 9184 & 24.75 \\
\hline Pentanucleotide & 365 & 0.16 & 14380 & 39.40 \\
\hline AAAAT & 126 & 0.05 & 7710 & 61.19 \\
\hline AAAAC & 31 & 0.01 & 830 & 26.77 \\
\hline AAAAG & 25 & 0.01 & 690 & 27.60 \\
\hline AAACC & 24 & 0.01 & 610 & 25.42 \\
\hline Others & 159 & 0.07 & 4540 & 28.55 \\
\hline Hexanucleotide & 311 & 0.13 & 11772 & 37.85 \\
\hline AGAGGG & 23 & 0.01 & 1146 & 49.83 \\
\hline AAAAAC & 16 & 0.01 & 510 & 31.88 \\
\hline AAGCCC & 12 & 0.01 & 468 & 39.00 \\
\hline AAAAAT & 12 & 0.01 & 636 & 53.00 \\
\hline Others & 248 & 0.10 & 9012 & 36.34 \\
\hline Total & 233844 & 100 & 3229055 & 13.81 \\
\hline
\end{tabular}

most abundant repeat motif (14.25\%), followed by (AG) $(7.95 \%),(\mathrm{AC})_{\mathrm{n}}(1.46 \%)$ and $(\mathrm{CG}) \mathrm{n}(0.01 \%)$. All ten possible combinations of TNRs were observed in the SSRs. Among them, the (AAG) $)_{\mathrm{n}}$ motif was the most common $(1.83 \%)$, followed by the (AAT) ${ }_{n}(1.08 \%), \quad(A G G)_{n}$ $(0.61 \%),(\mathrm{AAC})_{\mathrm{n}}(0.56 \%)$ and $(\mathrm{AGT})_{\mathrm{n}}(0.45 \%)$ motifs. 
Four main combinations of TTRs, four of PNRs and four of HNRs were also observed (Table 2). All the other repeat types were very rare in the $B$. oleracea genome.

A total of 1,026,766 SNPs were detected between 0188 and $02-12$, of these the A/G SNP type $(597,814$, $58.22 \%$ ) was the most abundant and the G/C SNP type was the least abundant $(72,115,7.02 \%)$. While the $\mathrm{A} / \mathrm{C}$ SNP type accounted for $21.96 \%(225,433)$ and the A/T SNP type accounted for $12.80 \%(131,404)$. A total of 2,200 SNP markers were transfered to SNAP markers for genotyping the mapping population.

A total of 1,096,647 EST were downloaded from NCBI. A total of 445,139 SSR loci were detected from the EST sequences (Table 3). The proportion for the MNRs and TNRs in Brassica EST sequences was higher than in B.oleracea genome sequences except AAT motif. The frequency of the most types of repeat units (DNRs, TTRs, PNRs and HNRs) in the genome was higher than that in ESTs except three motifs (AG, CG and AAAAAC). Especially AT motif frequency in the genome (14.25\%) was much higher than that in ESTs $(1.37 \%)$.

\section{Analysis of polymorphic markers}

To construct the map, a total of 8,497 markers were screened with the DNA from the 01-88 and 02-12 parental lines. Fifteen percent $(1,274)$ of the markers were polymorphic (Table 4), including 417 (12.34\%) SSRs and 646 (29.36\%) SNPs. The SNPs were more useful than the SSRs for map construction.

\section{Skewed segregation of markers}

Because of differences among genotypes in their responsiveness to microspore or anther culture, most of the Brassica linkage maps based on DH populations contain markers with skewed segregations [34-36]. In the present study, 1,227 of the 1,274 markers (96.31\%) that were polymorphic between the two parental lines were assigned to linkage groups. Of those, 449 (33.69\%) had skewed segregation patterns, including 203 (33.72\%) SSRs and 246 (39.36\%) SNPs (Table 5). There were segregation distortion regions (SDRs) in all of the linkage groups except $\mathrm{C} 03$ and $\mathrm{C} 04$, the markers in the SDRs were randomly distributed. C05, C06 and C09 with five SDRs each had the highest numbers. The longest SDR, with 76 markers, was on C02, where it covered 30.07\% of C02. The shortest SDR with only 10 markers was in C05 and C06 (Table 6).

\section{Construction of the high-density genetic map}

The genetic map that was constructed includes 1,227 markers (602 SSRs and 625 SNPs) assigned to nine linkage groups designated C01-C09 (Figure 2 and Additional file 1), the same as the number of haploid cabbage chromosomes
Table 3 Distribution of the SSR frequency in Brassica EST sequences

\begin{tabular}{|c|c|c|c|c|}
\hline Motifs & Number & $\begin{array}{l}\text { Percentage } \\
\text { (\%) }\end{array}$ & $\begin{array}{l}\text { Total length } \\
\text { (bp) }\end{array}$ & $\begin{array}{c}\text { Average } \\
\text { length (bp) }\end{array}$ \\
\hline Mononucletide & 339538 & 76.277 & 7614099 & 22.42 \\
\hline$A$ & 310831 & 69.828 & 7256120 & 23.34 \\
\hline C & 28707 & 6.449 & 357979 & 12.47 \\
\hline Dinucleotide & 55734 & 12.521 & 935952 & 16.79 \\
\hline$A G$ & 44403 & 9.975 & 756440 & 17.04 \\
\hline AT & 6090 & 1.368 & 99192 & 16.29 \\
\hline$A C$ & 5186 & 1.165 & 79618 & 15.35 \\
\hline CG & 55 & 0.012 & 702 & 12.76 \\
\hline Trinucleotide & 48202 & 10.829 & 818475 & 16.98 \\
\hline AAG & 17256 & 3.877 & 298896 & 17.32 \\
\hline AGG & 7389 & 1.660 & 123783 & 16.75 \\
\hline $\mathrm{ACT}$ & 5199 & 1.168 & 88563 & 17.03 \\
\hline ACC & 3878 & 0.871 & 62421 & 16.10 \\
\hline AAC & 3644 & 0.819 & 61962 & 17.00 \\
\hline AGT & 3433 & 0.771 & 58869 & 17.15 \\
\hline AGC & 2305 & 0.518 & 38754 & 16.81 \\
\hline ACG & 2063 & 0.463 & 33597 & 16.29 \\
\hline CCG & 1558 & 0.350 & 25122 & 16.12 \\
\hline AAT & 1477 & 0.332 & 26508 & 17.95 \\
\hline Tetranucleotide & 1026 & 0.230 & 23372 & 22.78 \\
\hline AAAG & 249 & 0.056 & 5784 & 23.23 \\
\hline AAAC & 164 & 0.037 & 3484 & 21.24 \\
\hline AAGG & 84 & 0.019 & 1912 & 22.76 \\
\hline AACG & 82 & 0.018 & 1844 & 22.49 \\
\hline Others & 447 & 0.100 & 10348 & 23.15 \\
\hline Pentanucleotide & 220 & 0.049 & 5980 & 27.18 \\
\hline AAACC & 40 & 0.009 & 1195 & 29.88 \\
\hline AAAAG & 36 & 0.008 & 935 & 25.97 \\
\hline AGAGG & 21 & 0.005 & 570 & 27.14 \\
\hline AAAAC & 20 & 0.004 & 515 & 25.75 \\
\hline Others & 103 & 0.023 & 2765 & 26.84 \\
\hline Hexanucleotide & 419 & 0.094 & 13704 & 32.71 \\
\hline AAAAAC & 42 & 0.009 & 1326 & 31.57 \\
\hline ACCTGC & 29 & 0.007 & 870 & 30.00 \\
\hline AAGGTG & 23 & 0.005 & 690 & 30.00 \\
\hline AGGAGT & 19 & 0.004 & 570 & 30.00 \\
\hline Others & 306 & 0.069 & 10248 & 33.49 \\
\hline Total & 445139 & 100 & 9411582 & 21.14 \\
\hline
\end{tabular}

$(2 \mathrm{n}=2 \mathrm{x}=18, \mathrm{n}=9)$. Only 47 markers (3.69\%) were not linked on the map. The map spanned a total of $1197.9 \mathrm{cM}$. Because the cabbage genome size is approximately $603 \mathrm{Mb}$ [37], the current map represents average genetic and physical intervals of $0.98 \mathrm{cM}$ and $503.3 \mathrm{Kbp}$ per marker, respectively, making it the most saturated linkage map for $B$. oleracea to date. 
Table 4 Characteristics of the primers used in this study

\begin{tabular}{lccc}
\hline Sources of primers & $\begin{array}{c}\text { Number of } \\
\text { primer pairs }\end{array}$ & $\begin{array}{c}\text { Number of } \\
\text { polymorphic } \\
\text { primer pairs }\end{array}$ & $\begin{array}{c}\text { Frequency of } \\
\text { polymorphism } \\
\text { primer pairs }\end{array}$ \\
\hline $\begin{array}{l}\text { Sequencing of } \\
\text { B. oleracea }\end{array}$ & 3378 & 417 & 12.34 \\
\hline $\begin{array}{l}\text { Resequencing of } \\
\text { B. oleracea }\end{array}$ & 2200 & 646 & 29.36 \\
\hline $\begin{array}{l}\text { Public markers of } \\
\text { B. oleracea }\end{array}$ & 551 & 52 & 9.44 \\
\hline $\begin{array}{l}\text { Associate Researcher } \\
\text { Zhuang in IVF CAAS }\end{array}$ & 1080 & 85 & 7.87 \\
\hline $\begin{array}{l}\text { Professer Liu Kede in } \\
\text { Huazhong }\end{array}$ & 268 & 15 & 5.60 \\
Agricultural University & & & \\
\hline BAC database of B. rapa & 292 & 19 & 6.51 \\
\hline Sequencing of B. rapa & 728 & 40 & 5.49 \\
\hline Total & 8497 & 1274 & 14.99 \\
\hline
\end{tabular}

The largest linkage group (C03) contained the largest number of markers (186) and spanned $161.8 \mathrm{cM}$, while the smallest linkage group (C09) contained the smallest number of markers (99) and spanned $126.3 \mathrm{cM}$. The average distance between adjacent markers went from $0.72 \mathrm{cM}(\mathrm{C06})$ to $1.43 \mathrm{cM}(\mathrm{C02})$. The distribution of SSRs ranged from 43 (C09) to 99 (C03), and the distribution of SNPs ranged from 56 (C09) to 87 (C03). Seven gaps with a distance $>5 \mathrm{cM}$ between adjacent markers were spread across $\mathrm{C} 02$, and seven gaps with distances $>10 \mathrm{cM}$ between adjacent markers occurred on six of the linkage groups: C01, C02, C07, C08 and C09 each with one gap, and $\mathrm{C06}$ with two gaps (Table 7). The results show that the marker loci were unevenly mapped in nine linkage groups (Figure 3).

\section{Distribution of markers along linkage groups}

Significant deviations from the random distribution of markers were observed for marker intervals of $1 \mathrm{cM}$, $2.5 \mathrm{cM}, 5 \mathrm{cM}, 10 \mathrm{cM}, 20 \mathrm{cM}$, and $40 \mathrm{cM}$. For a $1 \mathrm{cM}$ interval, the significant deviation $(\mathrm{P}<0.001)$ was shown in Figure 3, indicating that the markers were not randomly distributed in the Brassica oleracea linkage groups. Marker distribution for other intervals $(2.5 \mathrm{cM}$, $5 \mathrm{cM}, 10 \mathrm{cM}, 20 \mathrm{cM}$, and $40 \mathrm{cM}$ ) also showed clustering of markers $(\mathrm{P}<0.001)$ along linkage groups. The independent analysis for testing the random distribution of
Table 6 Distribution of markers in the segregation distortion regions in the linkage groups

\begin{tabular}{lcccc}
\hline $\begin{array}{l}\text { Linkage } \\
\text { groups }\end{array}$ & $\begin{array}{c}\text { Number of } \\
\text { distorted } \\
\text { markers }\end{array}$ & $\begin{array}{c}\text { Number of } \\
\text { SDRs }^{\mathbf{a}}\end{array}$ & $\begin{array}{c}\text { Number of the } \\
\text { longest SDRs }\end{array}$ & $\begin{array}{c}\text { Distance of the } \\
\text { longest } \\
\text { SDRs (cM) }\end{array}$ \\
\hline C01 & 86 & 4 & 44 & 12.37 \\
\hline C02 & 95 & 3 & 76 & 47.66 \\
\hline C03 & 16 & 0 & 0 & 0 \\
\hline C04 & 4 & 0 & 0 & 0 \\
\hline C05 & 49 & 5 & 10 & 4.08 \\
\hline C06 & 38 & 5 & 10 & 23.17 \\
\hline C07 & 26 & 1 & 16 & 11.26 \\
\hline C08 & 63 & 3 & 42 & 15.45 \\
\hline C09 & 72 & 5 & 37 & 20.25 \\
\hline Total & 449 & 26 & 235 & 134.24 \\
\hline
\end{tabular}

${ }^{\mathrm{a} S D R s,}$ segregation distortion regions.

SSR $(\mathrm{P}<0.001)$ and SNP $(\mathrm{P}<0.001)$ markers indicated deviations from the random distribution.

The distance between two adjacent markers on the linkage groups varied from 0 to $31.4 \mathrm{cM}$, with an average distance of $0.98 \mathrm{cM}$ between two adjacent markers (Figure 4; Table 7). This distance distribution reveals a strong skewness $(\mathrm{P}<0.001)$, further indicating the nonrandom distribution of the markers along the linkage groups (Figure 4). Among the 1,218 intervals on 9 different linkage groups, 886 intervals were smaller than $1 \mathrm{cM}$ (72.2\%), and 24 intervals were larger than $6 \mathrm{cM}(2.0 \%)$.

\section{Discussion}

Construction of high-density linkage map of $B$. oleracea This study was concerned with the construction and comprehensive analysis of a high-density linkage map of B. oleracea. The map spans $1197.9 \mathrm{cM}$ and is divided into nine linkage groups corresponding to the number of $B$. oleracea chromosomes, with an average distance of $0.98 \mathrm{cM}$ between adjacent markers. Significantly, of the 1,227 mapped markers, 1,063 (86.63\%) were sequencebased markers for B. oleracea.

The main purpose of constructing the map was to anchor and orient scaffolds onto the pseudochromosomes for the $B$. oleracea sequencing project. Approximately $83 \%$ of the B. oleracea genome has been assembled using

Table $\mathbf{5}$ Characteristics of the molecular markers used in mapping

\begin{tabular}{|c|c|c|c|c|c|c|}
\hline $\begin{array}{l}\text { Molecular } \\
\text { markers }\end{array}$ & $\begin{array}{l}\text { Number of } \\
\text { polymorphism } \\
\text { primers }\end{array}$ & $\begin{array}{c}\text { Number of } \\
\text { linked } \\
\text { markers }\end{array}$ & $\begin{array}{c}\text { Number of } \\
\text { unlinked } \\
\text { markers }\end{array}$ & $\begin{array}{c}\text { Frequency of } \\
\text { unlinked } \\
\text { markers (\%) }\end{array}$ & $\begin{array}{c}\text { Number of } \\
\text { distorted } \\
\text { markers }\end{array}$ & $\begin{array}{c}\text { Rate of } \\
\text { distorted } \\
\text { markers (\%) }\end{array}$ \\
\hline SSR & 628 & 602 & 26 & 4.14 & 203 & 33.72 \\
\hline SNP & 646 & 625 & 21 & 3.25 & 246 & 39.36 \\
\hline Total & 1274 & 1227 & 47 & 3.69 & 449 & 36.59 \\
\hline
\end{tabular}




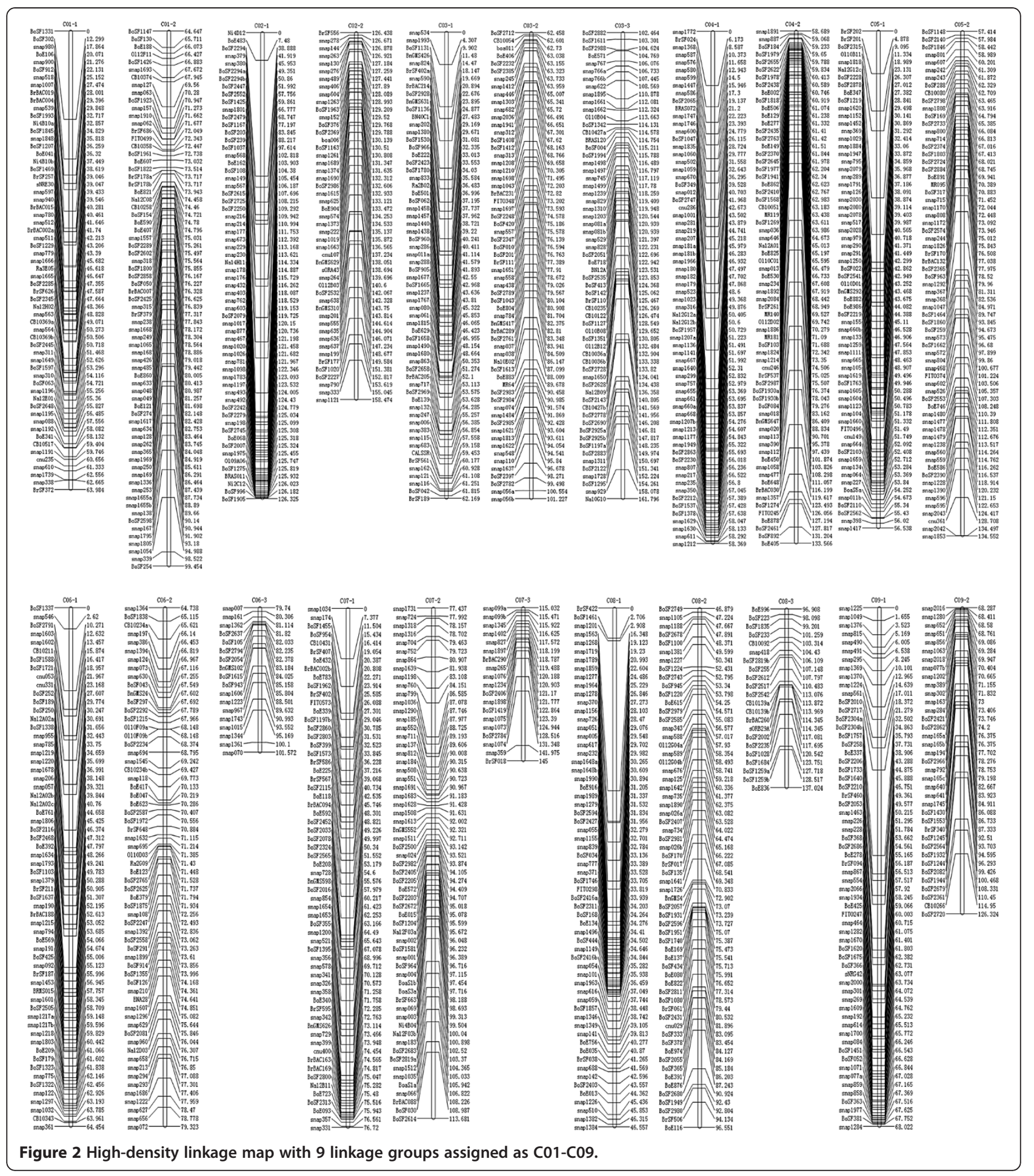

this high-density linkage map, and the results will be published in a future paper.

Ideally the average distance between adjacent markers should be short and the markers should be evenly distributed throughout the genome. However, many of the markers on the linkage maps of tomato [38], barley [39] and maize [40] have been reported to be clustered. Similarly, the markers on the $B$. oleracea genetic linkage map created in the present study are not evenly distributed.

SSRs are efficient anchor markers with high levels of polymorphism and single locations. They can be used 
Table 7 Distribution of molecular markers on the $B$. oleracea high-density genetic map

\begin{tabular}{|c|c|c|c|c|c|c|c|}
\hline \multirow[t]{2}{*}{ Chromosome } & \multirow{2}{*}{$\begin{array}{l}\text { Length } \\
\text { (cM) }\end{array}$} & \multirow{2}{*}{$\begin{array}{l}\text { Number of } \\
\text { markers }\end{array}$} & \multirow{2}{*}{$\begin{array}{l}\text { Number of } \\
\text { SSRs }\end{array}$} & \multirow{2}{*}{$\begin{array}{l}\text { Number of } \\
\text { SNPs }\end{array}$} & \multirow{2}{*}{$\begin{array}{l}\text { Average distance } \\
\text { between two } \\
\text { markers (cM) }\end{array}$} & \multicolumn{2}{|c|}{ Number of gaps $-D^{a}(c M)$} \\
\hline & & & & & & $5<\mathrm{D}<10$ & $\mathrm{D}>10$ \\
\hline C01 & 99.5 & 132 & 68 & 64 & 0.75 & 1 & 1 \\
\hline C02 & 158.5 & 111 & 48 & 63 & 1.43 & 7 & 1 \\
\hline $\mathrm{CO3}$ & 161.8 & 186 & 99 & 87 & 0.87 & 1 & 0 \\
\hline CO4 & 133.6 & 136 & 64 & 72 & 0.94 & 3 & 0 \\
\hline $\mathrm{C05}$ & 134.6 & 133 & 52 & 81 & 1.01 & 3 & 0 \\
\hline $\mathrm{CO6}$ & 101.6 & 142 & 72 & 70 & 0.72 & 1 & 2 \\
\hline $\mathrm{CO7}$ & 145.0 & 142 & 70 & 72 & 1.01 & 1 & 1 \\
\hline $\mathrm{C08}$ & 137.0 & 146 & 86 & 60 & 0.94 & 1 & 1 \\
\hline C09 & 126.3 & 99 & 43 & 56 & 1.28 & 0 & 1 \\
\hline Total & 1197.9 & 1227 & 602 & 625 & 0.98 & 18 & 7 \\
\hline
\end{tabular}

${ }^{\mathrm{a}} \mathrm{D}$, gap distance between adjacent markers.

to integrate different linkage maps and chromosomes. SSRs also make good probes for fluorescent situ hybridization (FISH) to integrate genetic and cytogenetic maps.

The main reason why the distribution of molecular markers is uneven is that some chromosomal regions in the parental lines lack polymorphisms. Therefore, the development of mapping populations from different crosses and the use of new molecular markers, including SNPs and SSRs are effective ways to fill in gaps between makers to obtain saturated genetic maps.

\section{Comparison with published maps of $B$. oleracea}

A total of 18 different genetic linkage maps of $B$. oleracea have been constructed (Table 8 ). The first substantial linkage map based on an $\mathrm{F}_{2}$ cross between cabbage and broccoli, contained a total of 258 RFLP markers and covered $820 \mathrm{cM}$ [9]. Since then, the construction of molecular genetic linkage maps of Brassica has developed rapidly. Kianian and Quiros [41] developed a map from an $\mathrm{F}_{2}$ that consisted of 92 RFLP and 16 isozyme markers covering over $747 \mathrm{cM}$ in 11 linkage groups. A linkage map consisting of 159 RFLP markers with a total distance of 921 cM was constructed from an $\mathrm{F}_{2}$ cross between cabbage and broccoli [8]. A $B$ oleracea genetic map consisting of 279 molecular markers and one phenotypic marker distributed along nine linkage groups (C01-C09) with a total distance of $891.4 \mathrm{cM}$ and a marker density of $3.2 \mathrm{cM} /$ marker has also been published [42]. The highest density Brassica oleracea linkage map developed by Gao et al. [43] comprised of 1,257 markers. Although this linkage map contained more markers than ours, most markers on their map were SRAP markers, which could not be transferred to other linkage map easily. The map constructed in this study comprised of markers which were SSR and SNP markers that were easy to transfer to other linkage maps.

The map produced in the present study contains the second largest number of transferable markers out of the 18 genetic linkage maps constructed thus far. The average genetic and physical intervals, however, are the shortest at $0.98 \mathrm{cM}$ and $503.3 \mathrm{~Kb}$ per marker, and the number of transferable markers on the map is more than on all the previously published genetic maps. In addition, because the mapping population was a doubled haploid (immortal) produced from a cross between cabbage varieties the map will enhance the efficiency of cabbage breeding, compared to the other maps that were produced from crosses between different varieties such as cabbage and broccoli, and cauliflower and kale. Therefore, this newly constructed map is not only important for research on the related characteristics of cabbage, but it will also contribute to the exchange of materials between laboratories and successive research in the future.

\section{The reason for segregation distortion}

Segregation distortion is defined as the frequencies of genotypes in offspring that do not conform to those predicted by the classical Mendel's law of inheritance. Genetic mapping studies have demonstrated that this phenomenon occurs in many species, including maize $[57,58]$, rice $[59,60]$ and cherimoya $[61]$; however, the cause of this marker skewing is still debated.

Skewed segregation of markers affects recombination values between markers which results in decreased accuracy of genetic maps and QTL mapping. The extent of skewness is related to the type of markers, the mapping population that was used, and the genetic relationships of the parents. In general, the skewness of co-dominant markers is less than dominant ones [62]. 
$\mathrm{C} 01$

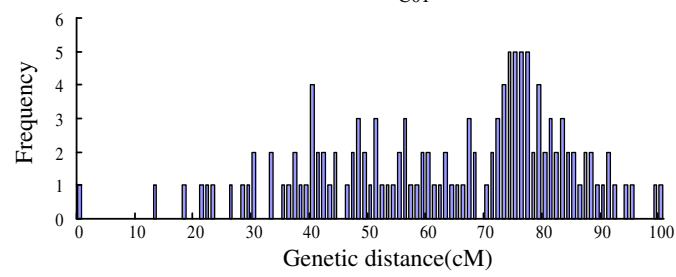

$\mathrm{C} 02$

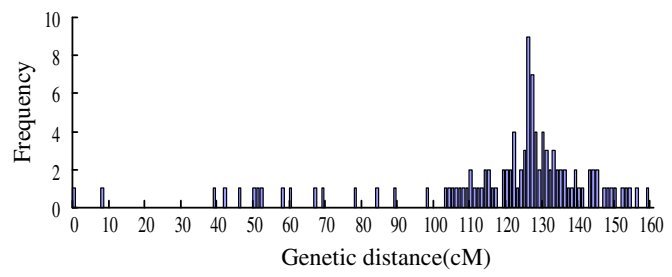

$\mathrm{C} 03$

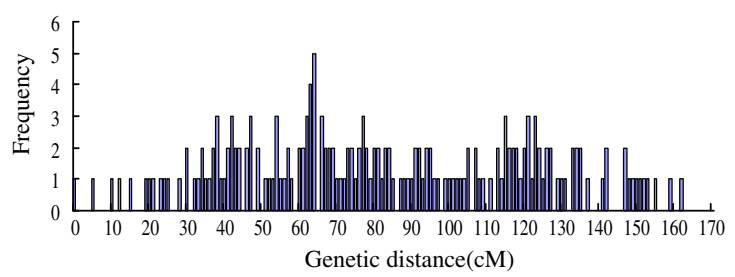

$\mathrm{C} 04$

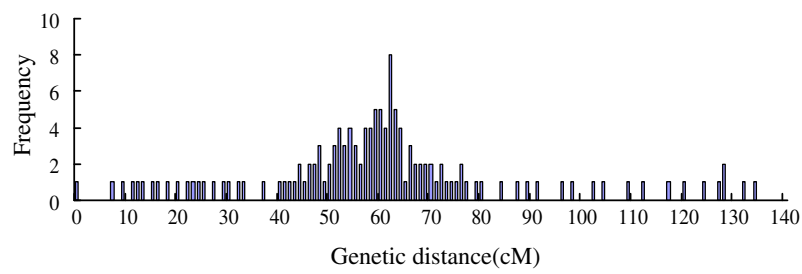

$\cos$

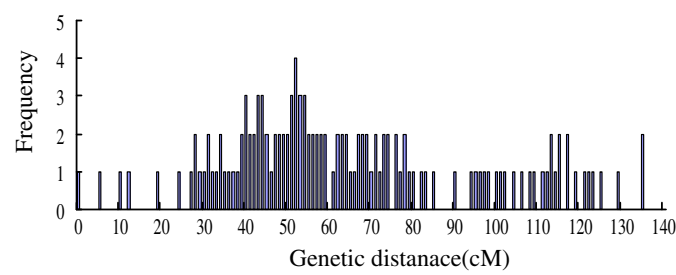

$\mathrm{C} 06$

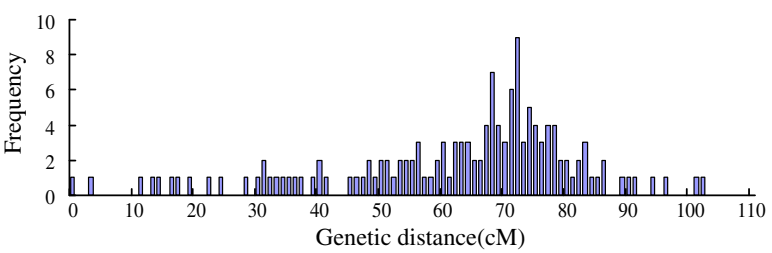

$\mathrm{C} 07$

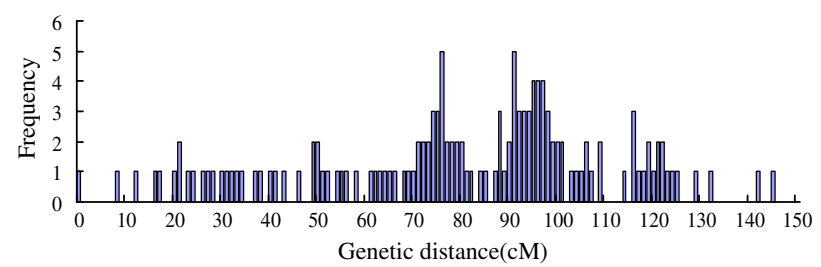

$\mathrm{C} 08$

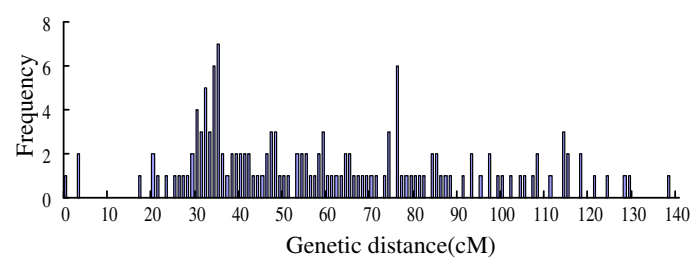

$\mathrm{C} 09$

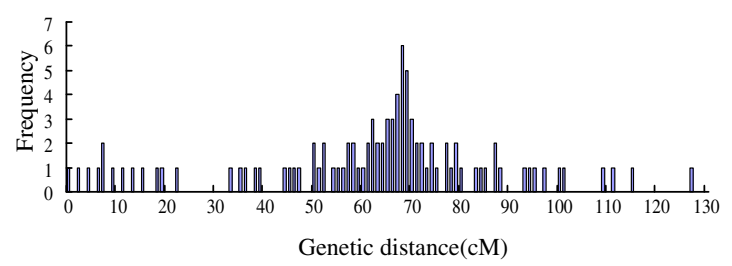

Figure $3 \mathrm{x}$-axis indicates position in each linkage group in 1cM interval and the $y$-axis indicates number of markers in the $1 \mathrm{cM}$ bin.

The skewed segregation ratio of recombinant inbred lines is higher than backcross populations $(\mathrm{BC})$ and doubled haploid populations $(\mathrm{DH})$. The $\mathrm{F}_{2}$ population has the lowest marker skewness. A low frequency of skewness implies that the parental genetic relationship is close [41].

Lyttle [63] suggested that skewed segregation was one of the engines of evolutionary processes, and that it may be related to the selection of gametophytes or sporophytes. Faure [64] proposed many possible reasons for this phenomenon: (1) the loci on chromosomes are not homologous or translocated, which impacts negatively on synapses in meiosis; (2) different selectivities of gametophyte and sporophyte; (3) interactions between adjacent and linked loci; and (4) non-homologous recombination, gene conversion, and/or transposon from parents [65]. Environmental factors and perhaps other factors may also have to be considered.

Skewed markers may be distributed among linkage groups either as individuals or as clusters. The individually 


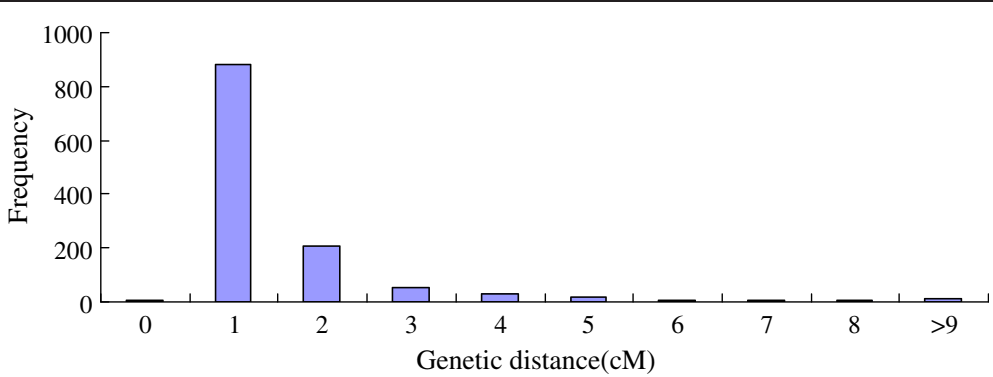

Figure 4 Distribution of map distance between two adjacent mapped makers.

segregated loci occur because of the emergence of systematic segregation [66] and are caused by point mutations. Often distorted markers are linked in clusters, suggesting that there has been selective process of gametophytes or sporophytes [61].

In the current study, we identified 26 distorted regions on linkage groups $\mathrm{C} 01, \mathrm{C} 02, \mathrm{C} 05, \mathrm{C} 06, \mathrm{C} 07$, $\mathrm{C} 08$ and C09. The SDRs were distributed as clusters, which is similar to the results of studies on other crops. The highest numbers of distorted SDR markers were found near the middle of the linkage groups, and the numbers gradually reduced towards the ends. In summary, studies of the linkage maps of rice, maize and other crops have shown that SDR loci may be linked to sterility genes and pollen suppressed genes which, in turn, affects the selection of partial gametophytes or sporophytes. It is important to note that while the phenomenon of skewed segregation was observed in $B$. oleracea, it requires further investigation.

\section{Conclusions}

The high-density linkage map of B. oleracea L. var. capitata was constructed with the aim of using it to anchor the assembled scaffolds to pseudochromosomes, and the assembly of the cabbage genome sequence (to be published soon) has been completed using this map. The map will also provide a useful resource for positional

Table 8 Comparison of the newly constructed map with previously published genetic linkage maps of $B$. oleracea

\begin{tabular}{|c|c|c|c|c|c|c|}
\hline & Population & Cross combination & Types of markers & Number of markers & $\begin{array}{l}\text { Map length } \\
\text { (cM) }\end{array}$ & References \\
\hline 1 & $\mathrm{~F}_{2}$ & Broccoli $\times$ Cabbage & RFLP & 258 & 820 & [9] \\
\hline 2 & $\mathrm{~F}_{2}$ & Cabbage $\times$ Chinese cabbage & RFLP & 201 & 1112 & [44] \\
\hline 3 & $3 F_{2}$ & $\begin{array}{c}\text { Collard } \times \text { Cauliflower Collard } \times \\
\text { Broccoli Kale } \times \text { Cauliflower }\end{array}$ & RFLP isozyme & 108 (integrated) & 747 & [41] \\
\hline 4 & $\mathrm{~F}_{2}$ & Cabbage $\times$ Broccoli & RFLP & 112 & 1002 & {$[45]$} \\
\hline 5 & $\mathrm{DH}$ & Broccoli $\times$ Chinese kale & PFLP & 303 & 875 & {$[7]$} \\
\hline 6 & $\mathrm{BC}_{1}$ & Chinese kale $\times$ Broccoli & RFLP RAPD isozyme & 138 & 747 & {$[46]$} \\
\hline 7 & $\mathrm{~F}_{2}$ & Cabbage $\times$ Broccoli & RFLP RAPD & 159 & 921 & [47] \\
\hline 8 & $\mathrm{DH}$ & Cabbage $\times$ Broccoli & RFLP AFLP & 92 & 165 & [48] \\
\hline 9 & $\mathrm{~F}_{2}$ & Cabbage $\times$ Chinese cabbage & $\begin{array}{l}\text { RFLP RAPD STS SCAR } \\
\text { Phenotypic isozyme }\end{array}$ & 310 & 1606 & [49] \\
\hline 10 & $\mathrm{~F}_{2}$ & Collard $\times$ Cauliflower & RFLP & 167 & 1738 & {$[50]$} \\
\hline 11 & $\mathrm{~F}_{2}$ & Cabbage $\times$ Kale & RAPD RFLP isozyme & 124 & 823.6 & [51] \\
\hline 12 & $2 \mathrm{DH}$ & $\begin{array}{c}\text { Chinese Kale } \times \text { Broccoli } \\
\text { Cauliflower } \times \text { Brussels sprouts }\end{array}$ & RFLP AFLP & 547 (integrated) & 893 & {$[52]$} \\
\hline 13 & $\mathrm{~F}_{2}$ & Chinese kale $\times$ Cabbage & RAPD & 96 & 555.7 & {$[53]$} \\
\hline 14 & $\mathrm{~F}_{2}$ & Cabbage $\times$ Broccoli & AFLP RAPD SSR & 405 & 731.9 & {$[54]$} \\
\hline 15 & $\mathrm{~F}_{2}$ & Kale $\times$ Broccoli & RFLP & 199 & 1226.3 & {$[55]$} \\
\hline 16 & $\mathrm{~F}_{2}$ & Cauliflower $\times$ Cauliflower & AFLP NBS & 255 & 668.4 & {$[56]$} \\
\hline 17 & $\mathrm{~F}_{2}$ & Broccoli $\times$ Cauliflowe & SRAP SSR & 1257 & 703 & [43] \\
\hline \multirow[t]{2}{*}{18} & $\mathrm{DH}$ & Chinese cabbage $\times$ Broccoli & RFLP SSR & 279 & 891.4 & {$[42]$} \\
\hline & $\mathrm{DH}$ & Cabbage $\times$ Cabbage & SSR SNP & 1227 & 1197.9 & This study \\
\hline
\end{tabular}


cloning, molecular breeding, and integration of information of genes and traits in B. oleracea.

\section{Additional file}

Additional file 1: Details of the positions, genetic distances, names, types and sequences of all the markers for the linkage groups on the cabbage linkage map.

\section{Competing interests}

The authors declare that they have no competing interests.

\section{Authors' contributions}

WW isolated samples, generated the SSR and SNP markers, analyzed marker data, and wrote and revised the manuscript. SH analyzed the sequencing and re-sequencing data, designed the SSR and SNP markers, and revised the manuscript. YL designed the study and critically reviewed the manuscript. ZF designed the study. $L Y, M Z$ and $Y Z$ generated and managed the plants. WH and SL coordinated and designed the study. SY developed the DH population. JS and AZ performed some of the experiments. All the authors have read and approved the final manuscript.

\section{Acknowledgments}

The study was supported by the National High Technology Research and Development Program (863 Program) (2012AA100105, 2012AA100104, 2007AA10Z174), the Earmarked Fund for Modern Agro-industry Technology Research System (CARS-25), and the Key Laboratory of Biology and Genetic Improvement of Horticultural Crops, Ministry of Agriculture.

\section{Author details}

${ }^{1}$ Institute of Vegetables and Flowers, Chinese Academy of Agricultural Sciences, Key Laboratory of Biology and Genetic Improvement of Horticultural Crops, Ministry of Agriculture, P.R.China. Beijing 100081, China. ${ }^{2}$ Institute of Oil Crops Research, Chinese Academy of Agriculture Sciences, Key Laboratory for Biological Sciences of Oil Crops, P.R.China. Ministry of Agriculture, Wuhan 430062, China.

Received: 1 March 2012 Accepted: 18 September 2012

Published: 3 October 2012

\section{References}

1. Al-Shehbaz IA: The tribes of cruciferae (Brassicaceae) in the southeastern united states. Arnold Arboretum 1984, 65:343-373.

2. Fahey JW, Talalay P: The role of crucifers in cancer chemoprotection. In Phytochemicals and Health. Edited by Gustin DL, Flores HE. Rockville: American Society of Plant Physiologists; 1995:87-93.

3. $U$ N: Genome-analysis in Brossica with special reference to the experimental formation of $B$. napus and its peculiar mode of fertilization. Japan J Bot 1935, 7:389-452.

4. Johnston JS, Pepper AE, Hall AE, Chen ZJ, Hodnett G, Drabek J, Lopez R, Price HJ: Evolution of genome size in Brassicaceae. Ann Bot 2005, 95(1):229-235.

5. Liu H: Studies on the breeding of yellow-seeded Brassica napus. Proceedings of the 6th International Rapeseed Congress Paris France 1983, 77:637-641.

6. Brassica information database. http://www.brassica.info/resource/maps/ published-data.php.

7. Bohuon E, Keith D, Parkin I, Sharpe A, Lydiate D: Alignment of the conserved C genomes of Brassica oleracea and Brassica napus. TAG Theor Appl Genet 1996, 93(5):833-839.

8. Camargo LEA, Williams PH, Osborn TC: Mapping of quantitative trait loci controlling resistance of Brassica oleracea to Xanthomonas campestris pv campestris in the field and glasshouse. Phytopathology 1995, 85:1296-1300.

9. Slocum M, Figdore S, Kennard W, Suzuki J, Osborn T: Linkage arrangement of restriction fragment length polymorphism loci in Brassica oleracea. TAG Theor App/ Genet 1990, 80(1):57-64.
10. Gupta P, Varshney R: The development and use of microsatellite markers for genetic analysis and plant breeding with emphasis on bread wheat. Euphytica 2000, 113(3):163-185.

11. Delourme R, Falentin C, Huteau V, Clouet V, Horvais R, Gandon B, Specel S, Hanneton L, Dheu J, Deschamps M: Genetic control of oil content in oilseed rape (Brassica napus L.). TAG Theor Appl Genet 2006, 113:1331-1345.

12. Padmaja KL, Arumugam N, Gupta V, Mukhopadhyay A, Sodhi Y, Pental D, Pradhan A: Mapping and tagging of seed coat colour and the identification of microsatellite markers for marker-assisted manipulation of the trait in Brassica juncea. TAG Theor Appl Genet 2005, 111:8-14.

13. Zhao J, Becker HC, Zhang D, Zhang Y, Ecke W: Conditional QTL mapping of oil content in rapesseed with respect to protein content and traits related to plant development and grain. TAG Theor Appl Genet 2006, 113:33-38.

14. Hyten DL, Cannon SB, Song Q, Weeks N, Fickus EW, Shoemaker RC, Specht JE, Farmer AD, May GD, Cregan PB: High-throughput SNP discovery through deep resequencing of a reduced representation library to anchor and orient scaffolds in the soybean whole genome sequence. BMC Genomics 2010, 11(1):38.

15. Rafalski A: Applications of single nucleotide polymorphisms in crop genetics. Curr Opin Plant Biol 2002, 5(2):94-100.

16. Liehter R: Effcient yield of embryoids by culture of isolated microspores of different Brassicaceae species. Plant Breed 1989, 103:119-123.

17. Doyle J, Doyle J: A rapid DNA isolation procedure for small quantities of fresh leaf tissue. Phytochemical bulletin 1987, 19(1):11-15.

18. BrassicaDB database. http://brassica.bbsrc.ac.uk/cgi-bin/ace/searches/ browser/BrassicaDB.

19. Lagercrantz $U$, Ellegren $H$, Andersson $L$ : The abundance of various polymorphic microsatellite motifs differs between plants and vertebrates. Nucleic Acids Res 1993, 21(5):1111-1115.

20. Lowe AJ, Jones AE, Raybould AF, Trick M, Moule CL, Edwards KJ: Transferability and genome specificity of a new set of microsatellite primers among brassica species of the $\mathrm{U}$ triangle. Molecular Ecology Notes 2002, 2:7-11.

21. Lowe AJ, Moule C, Trick M, Edwards K: Efficient large-scale development of microsatellites for marker and mapping applications in Brassica crop species. TAG Theor Appl Genet 2004, 108:1103-1112.

22. Iniguez-Luy FL, Voort AV, Osborn TC: Development of a set of public SSR markers derived from genomic sequence of a rapid cycling Brassica oleracea L. Genotype. TAG Theor Appl Genet 2008, 117(6):977-985.

23. Chen C, Mu Z, Kang-ning L, Yu-mei L, Li-mei Y, Yang-yong Z, Fei C, Pei-tian S, Zhi-yuan F: Development and utility of EST-SSR marker in cabbage. Acta Horticulturae Sinica 2010, 37(2):221-228.

24. Cheng X, Xu J, Xia S, Gu J, Yang Y, Fu J, Qian X, Zhang S, Wu J, Liu K: Development and genetic mapping of microsatellite markers from genome survey sequences in Brassica napus. TAG Theoretical and applied genetics 2009, 118(6):1121-1131.

25. MlcroSAtellite identification tool. http://pgrc.ipk-gatersleben.de/misa

26. Van Ooijen J, Voorrips R: JoinMap 3.0, Software for the calculation of genetic linkage maps, Plant research international. Wageningen, The Netherlands; 2001.

27. NCBl electronic PCR. http://www.ncbi.nlm.nih.gov/sutils/e-pcr.

28. Parallel biological systems. http://pga.mgh.harvard.edu/cgi-bin/snap3/ websnaper3.cgi.

29. Drenkard E, Richter BG, Rozen S, Stutius LM, Angell NA, Mindrinos M, Cho RJ, Oefner PJ, Davis RW, Ausubel FM: A simple procedure for the analysis of single nucleotide polymorphisms facilitates map-based cloning in arabidopsis. Plant Physiol 2000, 124:1483-1492.

30. Sanguinetti C, Dias NE, Simpson A: Rapid silver staining and recovery of PCR products separated on polyacrylamide gels. Biotechniques 1994, 17(5):914-921.

31. Stam P: Construction of integrated genetic linkage maps by means of a new computer package: join Map. Plant J 1993, 3(5):739-744.

32. Parkin IA, Sharpe AG, Keith DJ, Lydiate DL: Identification of the $A$ and $C$ genomes of amphiploid Brassica napus (oilseed rape). Genome 1995, 38:1122-1133

33. Kosambi D: The estimation of map distance from recombination values. Ann Hum Genet 1943, 12:172-175.

34. Ferreira M, Williams P, Osborn T: RFLP mapping of Brassica napus using doubled haploid lines. TAG Theor Appl Genet 1994, 89:615-621. 
35. Takahata Y, Keller WA: High frequency embryogenesis and plant regeneration in isolated microspore culture of Brassica oleracea L. Plant Sci 1991, 74:235-242.

36. Uzunova M, Ecke W, Weissleder K, Uzunova M, Ecke W, Weissleder K Röbbelen G: Mapping the genome of rapeseed (Brassica napus L.). I. Construction of an RFLP linkage map and localization of QTLs for seed glucosinolate content. TAG Theor Appl Genet 1995, 90:194-204.

37. Arumuganathan K, Earle E: Nuclear DNA content of some important plant species. Plant Mol Biol Rep 1991, 9(3):208-218.

38. Haanstra J, Wye C, Verbakel H, Meijer-Dekens F, Van den Berg P, Odinot P, Van Heusden A, Tanksley S, Lindhout P, Peleman J: An integrated high-density RFLP-AFLP map of tomato based on two Lycopersicon esculentum $\times$ L. pennellii F2 populations. TAG Theor App/ Genet 1999, 99:254-271.

39. Qi X, Stam P, Lindhout P: Use of locus-specific AFLP markers to construct a high-density molecular map in barley. TAG Theor App/ Genet 1998, 96(3):376-384

40. Vuylsteke M, Mark R, Antonise R, Bastiaans E, Senior ML, Stuber CW, Melchinger AE, Lubberstedt T, Xia XC, Stam P, Zabeau M, Kuiper M: Two high-density AFLP ${ }^{\circledR}$ linkage maps of Zea mays L.: analysis of distribution of AFLP markers. TAG Theoretical and applied genetics 1999, 99(6):921-935.

41. Kianian S, Quiros C: Generation of a Brassica oleracea composite RFLP map: linkage arrangements among various populations and evolutionary implications. TAG Theor App/ Genet 1992, 84(5):544-554.

42. Iniguez-Luy FL, Lukens L, Farnham MW, Amasino RM, Osborn TC: Development of public immortal mapping populations, molecular markers and linkage maps for rapid cycling Brassica Rapa and $B$. Oleracea. TAG Theor Appl Genet 2009, 120(1):31-43.

43. Gao M, Li G, Yang B, Qiu D, Farnham M, Quiros C: High-density Brassica oleracea linkage map: identification of useful new linkages. TAG Theor Appl Genet 2007, 115(2):277-287.

44. Landry B: A genetic map for Brassica oleracea based on RFLP markers detected with expressed DNA sequences and mapping of resistance genes to race 2 of Plasmodiophora brassicae (Woronin). Genome 1992, 35:409-420.

45. Camargo LEA: Mapping RFLP and quantitative trait loci in Brassica oleracea. TAG Theor App/ Genet 1996, 88:973-980.

46. Ramsay LD, Jennings DE, Kearsey MJ, Marshall DF, Bohuon EJR, Arthur AE, Lydiate DJ: The construction of a substitution library of recombinant backcross lines in Brassica oleracea for the precision mapping of quantitative trait loci. Genome 1996, 39(3):558-567.

47. Camargo L, Savides L, Jung G, Nienhuis J, Osborn T: Location of the self-incompatibility locus in an RFLP and RAPD map of Brassica oleracea. J Hered 1997, 88(1):57.

48. Voorrips $\mathrm{R}$, Jongerius $\mathrm{M}$, Kanne $\mathrm{H}$ : Mapping of two genes for resistance to clubroot (Plasmodiophora brassicae) in a population of doubled haploid lines of Brassica oleracea by means of RFLP and AFLP markers. TAG Theor Appl Genet 1997, 94(1):75-82.

49. Cheung W, Champagne G, Hubert N, Landry B: Comparison of the genetic maps of Brassica napus and Brassica oleracea. TAG Theor Appl Genet 1997, 94(5):569-582

50. Hu J, Sadowski J, Osborn TC, Landry BS, Quiros CF: Linkage group alignment from four independent (Brassica oleracea) RFLP maps. Genome 1998, 41(2):226-235.

51. Moriguchi K, Kimizuka-Takagi C, Ishii K, Nomura K: A genetic map based on RAPD, RFLP, isozyme, morphological markers and QTL analysis for clubroot resistance in Brassica oleracea. Breed Sci 1999, 49(4):257-265.

52. Sebastian R, Howell E, King G, Marshall D, Kearsey M: An integrated AFLP and RFLP Brassica oleracea linkage map from two morphologically distinct doubled-haploid mapping populations. TAG Theor App/ Genet 2000, 100(1):75-81.

53. Chen $\mathrm{S}$, Wang $\mathrm{X}$ : Construction a RAPDs linkage map between Chinese kale and cabbage. Acta Horticulturae Sinica 2002, 29(3):229-232.

54. Farinho M, Coelho P, Carlier J, Svetleva D, Monteiro A, Leitao J: Mapping of a locus for adult plant resistance to downy mildew in broccoli (Brassica oleracea var. Italica). TAG Theor Appl Genet 2004, 109(7):1392-1398.

55. Rocherieux J, Glory P, Giboulot A, Boury S, Barbeyron G, Thomas G, Manzanares-Dauleux M: Isolate-specific and broad-spectrum QTLs are involved in the control of clubroot in Brassica oleracea. TAG Theor App Genet 2004, 108(8):1555-1563.
56. Gu Y, Zhao QC, Sun DL, Song WQ: Construction of genetic linkage map and localization of NBS-LRR like resistance gene analogues in cauliflower (Brassica oleracea var. Botrytis). Yi Chuan 2007, 29(6):751-757.

57. Lu H, Romero-Severson J, Bernardo R: Chromosomal regions associated with segregation distortion in maize. TAG Theor Appl Genet 2002, 105:622-628.

58. Senior M, Chin E, Lee M, Smith J, Stuber C: Simple sequence repeat markers developed from maize sequences found in the GENBANK database: Map construction. Crop Sci 1996, 36:1676-1683.

59. Bing Z, Qi-Ming D, Qi-Jun Z, Jie-Qin L, Shao-Ping Y, Yong-Shu L, Yong P, Ping L: Analysis of segregation distortion of molecular markers in F2 population of rice. Acta Genetica Sinica 2006, 33:449-457.

60. Wang C, Zhu C, Zhai H, Wan J: Mapping segregation distortion loci and quantitative trait loci for spikelet sterility in rice (oryza sativa L.). Genet Res 2005, 86:97-106.

61. Perfectti F, Pascual L: Segregation distortion of isozyme loci in cherimoya (annona cherimola mill). TAG Theor App/ Genet 1996, 93(3):440-446.

62. Lorieux M: Maximum-likelihood models for mapping genetic markers showing segregation distortion.2.F2 populations. TAG Theor App/ Genet 1995, 90:81-89.

63. Lyttle TW: Segregation distorters. Annu Rev Genet 1991, 25(1):511-581.

64. Faure S, Noyer J, Horry J, Bakry F, Lanaud C: A molecular marker-based linkage map of diploid bananas (Musa acuminata). TAG Theor Appl Genet 1993, 87(4):517-526.

65. Knox M, Ellis T: Excess heterozygosity contributes to genetic map expansion in pea recombinant inbred populations. Genetics 2002, 162(2):861.

66. Sibov ST, de Souza CL Jr, Garcia AA, Silva AR, Mangolin CA, Benchimol LL, De Souza AP: Molecular mapping in tropical maize (Zea Mays L.) using microsatellite markers. 2. Quantitative trait loci (QTL) for grain yield, plant height, ear height and grain moisture. Hereditas 2003, 139(2):96-106

doi:10.1186/1471-2164-13-523

Cite this article as: Wang et al:: Construction and analysis of a highdensity genetic linkage map in cabbage (Brassica oleracea L. var. capitata). BMC Genomics 2012 13:523.

\section{Submit your next manuscript to BioMed Central and take full advantage of:}

- Convenient online submission

- Thorough peer review

- No space constraints or color figure charges

- Immediate publication on acceptance

- Inclusion in PubMed, CAS, Scopus and Google Scholar

- Research which is freely available for redistribution 